\title{
Hypertensive Retinopathy in Normotensive Blacks: About 3 Cases
}

\author{
Benedicte Carine Boka, Iklo Coulibaly, Hermann Yao, Ghyslain Ouffouet, \\ Marie-Paule Bernadette Ncho-Mottoh, Arnaud Kouadio Ekou \\ Institute of Cardiology, Abidjan, Cote d'Ivoire \\ Email: benedicteboka@yahoo.fr, iklocoulibaly@yahoo.fr, ghisouffoue@yahoo.fr, nchomottoh@yahoo.fr, ekouarno@yahoo.fr
}

How to cite this paper: Boka, B.C., Coulibaly, I., Yao, H., Ouffouet, G., Ncho-Mottoh, M.-P.B. and Ekou, A.K. (2018) Hypertensive Retinopathy in Normotensive Blacks: About 3 Cases. World Journal of Cardiovascular Diseases, 8, 381-389.

https://doi.org/10.4236/wjcd.2018.87037

Received: May 29, 2018

Accepted: July 27, 2018

Published: July 30, 2018

Copyright $\odot 2018$ by authors and Scientific Research Publishing Inc. This work is licensed under the Creative Commons Attribution International License (CC BY 4.0).

http://creativecommons.org/licenses/by/4.0/

\begin{abstract}
In case of hypertension, hypertensive retinopathy is normally an indicator of target organ damage. This sign can be frequently detected even in normotensive subjects. Among 94 normotensive volunteers chosen with regard of the hypertensive status of their parents, we could report the case of 3 black women who had hypertensive retinopathy. As changes in retinal microvasculature precede other signs of damage, we suggest fundus photography routine to be performed more frequently in assessing cardiovascular risks in hypertensive individual and their offspring, especially in black African population, where hypertension is severe.
\end{abstract}

\section{Keywords}

Hypertensive Retinopathy-Normotensive-Blacks

\section{Introduction}

Systemic hypertension affects approximately $40 \%$ of the population worldwide and is the single most important preventable risk factor for cardiovascular diseases [1]. In Cote d'Ivoire, latest data found a prevalence of $21 \%$ in the region of lagoons [2]. Its determinism combines environmental and genetic factors [3].

Qualified as a silent killer, hypertension is dreadful regarding his impact on targets organs including eyes. Hypertension-related fundus abnormalities can be classified as hypertensive retinopathy, choroidopathy, and optic neuropathy [4]. A retinal examination to look for retinopathy signs is intended to determine the presence of organic lesions in persons with hypertension and to assess the cardiovascular risk level [5] [6].

Frequently, hypertensive retinopathy can be detected even in normotensive subjects [7] [8] [9]. 
Retinal blood vessel caliber is influenced by physiological (age, sex, race, blood pressure, blood glucose, body mass index) and pathological (atherosclerosis, dyslipidemia, smoking) determinants [10].

We conducted a survey in normotensives blacks among whom we found 3 women who had hypertensive retinopathy.

To our knowledge, this is the first case of hypertensive retinopathy reported in normotensive subjects in Cote d'Ivoire.

\section{Subjects and Methods}

The study protocol was approved by the Ethics committee of the Abidjan Cardiology Institute (ACI). The written consent of each participant involved in the study was obtained.

Subjects were selected from ACI workers. Participants underwent standardized evaluation of cardiovascular risk factors, ambulatory blood pressure measure (ABPM) to establish their hypertensive statut and funduscopy to show retinal changes associated with hypertension. We classified them regarding either their parents were hypertensives or not.

\subsection{Inclusion Criteria}

- being apparently normotensive

- up to 18 and less or equal to 60 years old

- assessment of relative's tensional status

\subsection{Exclusion Criteria}

- Presence of a cardiovascular pathology

- Exposure to medication able to interfere with cardiovascular system

- Menopausal, pregnant or breast-feeding Woman in the previous 12 months

Tensional status of the relatives was established at the end of an interrogation. Relatives had to be the biological ones. They were considered as hypertensive if the hypertension was essential and had been diagnosed before the age of 60 years and for more than 1 year.

We classified our population in 3 subgroups:

- descendants of two hypertensives parents $(\mathrm{PH}++)$

- descendants of a single hypertensive parent $(\mathrm{PH}+-)$

- descendants of normotensive parents (PH --)

\subsection{Cardiovascular Risk Factors Assessment}

Personal history of diabetes, cigarette smoking, alcohol consumption, and use of oral contraception were noticed from auto-administered questionnary.

Blood samples were collected after 12 hours of fasting and processed for total cholesterol, HDL cholesterol, triglycerides, and glucose.

Height and weight were measured for calculation of body mass index that was computed as weight divided by height squared. 


\subsection{Blood Pressure Level Assessment}

It was defined regarding systolic blood and diastolic blood pressure at office and in ambulatory. We added the blood pressure load and the dipping level according to the guidelines [11].

Hypertension was defined as systolic blood pressure $\geq 140 \mathrm{mmHg}$ and or diastolic blood pressure $\geq 90 \mathrm{mmHg}$.

ABPM was done by 2 devices of different brands, "Schiller" and "Mobil O Graph" a day of usual activity of the subject for operational reasons. The armband adapted to the circumference of the limb was placed on the not dominant arm in a comfortable way. The blood pressure was measured all the 15 minutes during the day; the subject being warned of the starting up of a measure by a beep so that he can relax the arm. At night, measures were made every $30 \mathrm{mi}-$ nutes and the beep disappeared to limit the disturbances of sleep. During the day, the device recorded 4 measures and 2 measures during night per hour.

Systolic and diastolic blood pressure were measured as well as the heart rate. The blood pressure load defined by the percentage of measures of blood pressure exceeding reference values. A value below $33 \%$ was considered as normal.

Twenty-four hours later, the device was removed and data transferred to a computer using of a cable. The recording was considered acceptable if it contained at least $80 \%$ of valid measures or at least 40 measures and if there was not successive 2 hours without measures.

Reference values for the blood pressure were: [12] [13].

- average: $130 / 80 \mathrm{mmHg}$

- daily: $135 / 85 \mathrm{mmHg}$

- night: $120 / 70 \mathrm{mmHg}$

The data analysis of the ABPM had to specify the notion of night dipping. It is a physiological reduction in the level of the systolic andlor diastolic blood pressure at least $10 \%$ to $20 \%$ during sleeping. Subjects were considered as:

- not dipper for a reduction in blood pressure night values between $0 \%$ and 9.99\%;

- reverse dipper for an increase in blood pressure night values;

- extreme dipper for a reduction of more than $20 \%$ in blood pressure night values.

\subsection{Hypertensive Retinopathy Assessment}

Several classifications have been proposed.

We preferred to choose the one proposed by Kirkendall (because its permit to see the difference between modification due to hypertension and arteriosclerosis) to the [14] famous graded classifications of hypertensive retinopathy by Keith-Wagener-Barker and Scheie [15] which is difficult to use in clinical practice.

Retinal microvasculature was analysed after administration of a drug named tropicamide: mydriaticum ${ }^{\bullet}$. 


\subsection{Statistical Analysis}

1) Categorical variables are expressed as a percentage;

2) Continuous variables are expressed as mean $+/-$ standard deviation;

3) The comparison of proportion used the chi-square test;

4) The relation between the family history of the subjects and the different characteristics was tested by an analysis of the variance with threshold of significance $\mathrm{p}<0.05$.

When the numbers were $<5$, the $\mathrm{p}$ value was no longer usable.

Data processing was done using SPSS software and version 7 of EPI Info.

\section{Results}

\subsection{Sociodemography}

Among the 400 workers of the CIA, only 94 persons were agreed and matched the inclusion criteria. Among them, there were 35 (37\%) men and 59 (63\%) women leading to a sex ratio of 0.59 .

\subsection{Cardiovascular Risk Factors}

Cardiovascular risk factors were dominated by sedentary lifestyle, overweight, obesity and dyslipidemia.

N.B. A subject could have several cardiovascular risk factors.

\subsection{Blood Pressure Level}

The average age was 36.1 years, it was a young population.

ABPM measures were normal in $84 \%$ of subjects.

The fundus examination found 3 cases of hypertensive retinopathy.

\subsection{Hypertensive Retinopathy}

These were 3 nurses with no associated cardiovascular risk factors. They had normal blood pressure figures but abnormalities in dipping and blood pressure load.

\section{Discussion}

Within our sample, there were 35 (37\%) men, the mean age was 36.1 years. Finally, only $84 \%$ of them had a normal blood pressure profile (Table 1).

Overweight, obesity and dyslipidemia were mains cardiovascular risk factors (Figure 1). We found 3 women with retinopathy. In the latter, potential confounding factors were excluded.

Among these 3 subjects, 2 had 2 hypertensive's parents (Table 2). Despite normal value of blood pressure in both at the office and at the ambulatory measurement, their blood pressure profile reveals high blood pressure load and a lack of nocturnal dipping.

In fact, some authors report that high systolic blood pressure loads were associated with a higher prevalence of hypertensives retinopathies compared to a 


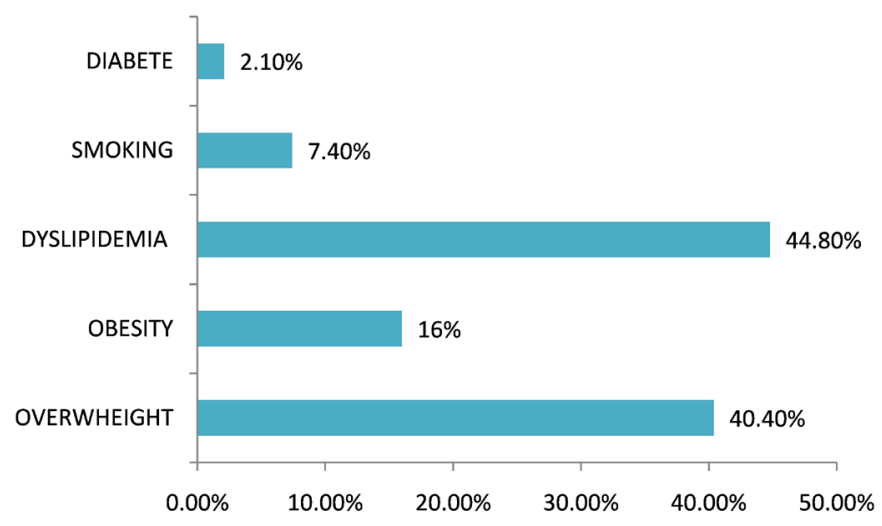

Figure 1. Cardiovascular risk factors in the general study.

Table 1. Characteristics and results of the ambulatory measure of the blood pressure and the fundoscopy in the population.

\begin{tabular}{ccccc}
\hline & & & & TOTAL \\
\hline Parental status (n) & $\mathrm{PH}--(26)$ & $\mathrm{PH}+-(43)$ & $\mathrm{PH}++(25)$ & 94 \\
\hline Mean age (years) & $36+/-7$ & $35+/-7$ & $37+/-8$ & 36.1 \\
Normal blood pressure profile & $21(80.8 \%)$ & $38(88.4 \%)$ & $20(76.9 \%)$ & $79(84 \%)$ \\
Normal dipping & $8(31 \%)$ & $21(49 \%)$ & $10(40 \%)$ & $39(41 \%)$ \\
Normal blood pressure load & $14(54 \%)$ & $28(65 \%)$ & $13(52 \%)$ & $55(59 \%)$ \\
Retinopathy & $1(3.8 \%)$ & 0 & $2(8 \%)$ & $3(3.19 \%)$ \\
\hline
\end{tabular}

Table 2. Characteristics of subjects having retinopathy based on parental status.

\begin{tabular}{lccc}
\hline Parental status Characters & $\mathrm{PH}--(\mathrm{n}=1)$ & $\mathrm{PH}++(\mathrm{n}=2)$ & \\
Mean age (years) & 39 & 29 & \\
Female & 1 & 25.01 & TOTAL $(\mathrm{n}=3)$ \\
BMI & 25.77 & 0.69 & \\
LDL cholesterol & 1.34 & $\mathrm{PH}+-$ & 0.41 \\
HDL cholesterol & 0.48 & 0.83 & \\
Glycemia & 0.72 & 0 & $3(100 \%)$ \\
Smoking & 0 & $2(67 \%)$ & $1(33 \%)$ \\
\hline & $1(33 \%)$ & $1(33 \%)$ & $2(67 \%)$ \\
Normal blood pressure profile & - & $1(33 \%)$ & \\
Elevated blood pressure load & $1(33 \%)$ & & \\
lack of dipping & & & \\
\hline
\end{tabular}

$\mathrm{PH}--=$ no hypertensive parent; $\mathrm{PH}++=2$ hypertensive parents; $\mathrm{PH}-+=1$ hypertensive parent $\mathrm{BMI}=$ body mass index.

subgroup with low systolic blood pressure loads in a population with moderate hypertension [16]. We can conclude with these authors that regardless of 24 hours blood pressure level, high blood pressure loads are associated with a poor prognosis.

However, according to Liu [17], the effect of blood pressure on target organ involvement appears to be related to the level of blood pressure.

Nevertheless, blood pressure loads appear as a determining element in the visceral repercussions of hypertension. 
These retinopathies which occurs despite normal blood pressure figures at office and at ambulatory measure let us think that the lack of dipping may play a bad role in the development of target organ damage. We underline here the prognostic role of the lack of dipping.

Indeed, Spanish authors [18] in a cohort study involving normotensive and hypertensive subjects found that the risk of a major cardiovascular event was not only influenced by the increase in blood pressure figures but also by lack of dipping in hypertensive as well as in normotensive subjects.

The relationship between hypertension and the prevalence of retinopathy is low amongst Afro-Caribbeans [19]. In his study, Wong showed that hypertensive retinopathy, is as common among African Americans as among Caucasian living in the United States, with high prevalence in people with and without hypertension [9].

The usefulness of hypertensive retinopathy grading as a clinical tool to assess the risk of systemic complications is unclear. According to some authors, hypertensive retinopathy reflects microvascular damage resulting mainly from elevated blood pressure, and is a marker of subclinical cerebral disease and is associated with risk of stroke [20]-[26].

Including Magnetic Resonance Imaging (MRI) defined cerebral infarcts, incident clinical stroke, ischemic strokes, and symptomatic and subclinical silent lacunar infarcts in healthy populations [22] [24] [25] [26].

However, the value of a retinal examination remains unclear as different classifications of hypertensive retinopathy (e.g., Keith Wagner Barker classification) are difficult to use in clinical practice, and a clinical ophthalmoscopic examination has low reliability and reproducibility [27] [28].

We can conclude with Wong that the presence of these retinal microvascular changes may be consider as indication of additional vascular risk among those conferred by traditional cardiovascular risk factors [29].

\section{Evolution and Limit}

There is no consensus on the treatment of hypertensive retinopathy in normotensive. Our subjects were not treated, we decide to follow them by a regular $\mathrm{ABPM}$ and monitoring of associated cardiovascular risk factors to initiate treatment if necessary.

The limits of this study may be the number of participants.

\section{Conclusions}

High Blood Pressure is a major cardiovascular risk factor causing end-organ damage including retinopathy. Because retinal microvasculature changes precede other signs of damage, we suggest more routine use of fundus for cardiovascular risk assessment in hypertensive subjects and their offspring, especially in blacks, where hypertension is severe.

If in hypertensive subjects, early recognition of hypertensive retinopathy is an 
important step in the risk stratification, what about normotensives subjects? Presence of retinopathy may be an indication to introduce antihypertensive treatment in some subjects (offsprings of hypertensives). In the screening of hypertensive offsprings, we suggest the integration of blood pressure load and the dipper profile.

\section{Conflicts of Interest}

The authors declare no conflicts of interest regarding the publication of this paper.

\section{References}

[1] The World Health Organisation (2017) A Global Brief on Hypertension, Silent Killer, Global Public Health Crisis.

http://ish-world.com/news/a/World-Health-Organization-A-Global-Brief-on-Hype rtension/consult\%C3\%A9\%20le/

[2] World Health Organization (2014) Geneva, Côte d'Ivoire. http://www.who.int/ncds/surveillance/steps/Cotedivoire_2005.pdf

[3] Jeunemaitre, X. and Gimenez-Roqueplo, A.P. (2002) Génétique et hypertension artérielle: Trois approches pour décrypter une maladie complexe. Bulletin de L'Académie Nationale de Médecine, 186, 1595-1609.

[4] Tso, M.O. and Jampol, L.M. (1982) Pathophysiology of Hypertensive Retinopathy. Ophthalmology, 89, 1132-1145. https://doi.org/10.1016/S0161-6420(82)34663-1

[5] Chobanian, A.V., Bakris, G.L., Black, H.R., et al. (2003) The Seventh Report of the Joint National Committee on Prevention, Detection, Evaluation, and Treatment of High Blood Pressure: The JNC 7 Report. JAMA, 289, 2560-2572. https://doi.org/10.1001/jama.289.19.2560

[6] Ong, Y.-T., Wong, T.Y., Klein, R., et al. (2013) Hypertensive Retinopathy and Risk of Stroke. Hypertension, 62, 706-711. https://doi.org/10.1161/HYPERTENSIONAHA.113.01414

[7] Wang, S., Xu, L., Jonas, J.B., et al. (2009) Major Eye Diseases and Risk Factors Associated with Systemic Hypertension in Adult Chinese Population: The Beijing Eye Study. Ophtalmology, 116, 2373-2380. https://doi.org/10.1016/j.ophtha.2009.05.041

[8] Klein, R., Klein, B. and Moss, S. (1993) Blood Pressure, Hypertension and Retinopathy in a Population. Transactions of the American Ophthalmological Society, 91, 207-222.

[9] Wong, T.Y., Klein, R., Bruce, B., et al. (2003) Racial Differences in the Prevalence of Hypertensive Retinopathy. Hypertension, 41, 1086-1091. https://doi.org/10.1161/01.HYP.0000064181.63546.53

[10] Dumitrescu, A.G., Voinea, L., Badarau, I.A., et al. (2017) Update on Retinal Vascular Caliber. Romanian Journal of Ophthalmology, 61, 171-180. https://doi.org/10.22336/rjo.2017.32

[11] O’Brien, E., Coasts, A., Owens, P., et al. (2000) Use and Interpretation of Ambulatory Blood Pressure Monitoring: Recommendations of the British Hypertension Society. BMJ, 320, 1128-134. https://doi.org/10.1136/bmj.320.7242.1128

[12] Staessen, J.A., Fagard, R., Thijs, L., et al. (1995) A Consensus View on the Technique of Ambulatory Blood Pressure Monitoring. The Fourth International Con- 
sensus Conference on 24-Hour Ambulatory Blood Pressure Monitoring. Hypertension, 26, 912-918. https://doi.org/10.1161/01.HYP.26.6.912

[13] Fagard, R.H. (2009) Dipping Pattern of Nocturnal Blood Pressure in Patients with Hypertension Disclosures. Expert Review of Cardiovascular Therapy, 7, 599-605. https://doi.org/10.1586/erc.09.35

[14] Wong, T.Y., Klein, R., Klein, B.E., et al. (1975) Retinal Changes of Hypertension. In: Kirkendall, W.M., Ed., The Eye and Systemic Disease, CV Mosby, St Louis, 212-222.

[15] Keith, N.M., Wagener, H.P. and Barker, N.W. (1939) Somme Different Types of Essential Hypertension: Their Course and Prognosis. The American Journal of the Medical Sciences, 197, 332-343. https://doi.org/10.1097/00000441-193903000-00006

[16] Mule, G., Nardi, E., Andronico, G., et al. (2001) Relationships between 24h Blood Pressure Load and Target Organ Damage in Patients with Mild-to-Moderate Essential Hypertension. Blood Pressure Monitoring, 6, 115-123. https://doi.org/10.1097/00126097-200106000-00001

[17] Liu, M., Li, Y., Wei, F.F., et al. (2013) Is Blood Pressure Load Associated, Independently of Blood Pressure Level, with Target Organ Damage? Journal of Hypertension, 31, 1812-1818. https://doi.org/10.1097/HJH.0b013e3283624f9b

[18] Hermida, R.C., Ayala, D.E., Mojón, A., et al. (2013) Blunted Sleep-Time Relative Blood Pressure Decline Increases Cardiovascular Risk Independent of Blood Pressure Level: The "Normotensive Non-Dipper" Paradox. Chronobiology International, 30, 87-98. https://doi.org/10.3109/07420528.2012.701127

[19] Sharp, P.S., et al. (1995) The EURODIAB IDDM Complications Study Group. Retinopathy in Afro-Caribbeans and Europeans: Prevalence and Risk Factor Relationships. Hypertension, 25, 1322-1325. https://doi.org/10.1161/01.HYP.25.6.1322

[20] Wong, T.Y., Klein, R., Nieto, F.J., et al. (2003) Retinal Microvascular Abnormalities and 10-Year Cardiovascular Mortality: A Population-Based Case-Control Study. Ophthalmology, 110, 933-940. https://doi.org/10.1016/S0161-6420(03)00084-8

[21] Mitchell, P., Wang, J.J., Wong, T.Y., et al. (2005) Retinal Microvascular Signs and Risk of Stroke and Stroke Mortality. Neurology, 65, 1005-1009. https://doi.org/10.1212/01.wnl.0000179177.15900.ca

[22] Cooper, L.S., Wong, T.Y., Klein, R., et al. (2006) Retinal Microvascular Abnormalities and MRI-Defined Subclinical Cerebral Infarction: The Atherosclerosis Risk in Communities Study. Stroke, 37, 82-86. https://doi.org/10.1161/01.STR.0000195134.04355.e5

[23] Witt, N., Wong, T.Y., Hughes, A.D., et al. (2006) Abnormalities of Retinal Microvascular Structure and Risk of Mortality from Ischemic Heart Disease and Stroke. Hypertension, 47, 975-981. https://doi.org/10.1161/01.HYP.0000216717.72048.6c

[24] Wong, T.Y., Klein, R., Couper, D.J., et al. (2001) Retinal Microvascular Abnormalities and Incident Stroke: The Atherosclerosis Risk in Communities Study. The Lancet, 358, 1134-1140. https://doi.org/10.1016/S0140-6736(01)06253-5

[25] Wong, T.Y., Klein, R., Sharrett, A.R., et al. (2002) Cerebral White Matter Lesions, Retinopathy, and Incident Clinical Stroke. JAMA, 288, 67-74. https://doi.org/10.1001/jama.288.1.67

[26] Yatsuya, H., Folsom, A.R., Wong, T.Y., et al. (2010) Retinal Microvascular Abnormalities and Risk of Lacunar Stroke: Atherosclerosis Risk in Communities Study. Stroke, 41, 1349-1355. https://doi.org/10.1161/STROKEAHA.110.580837 
[27] Van den Born, Hulsman, C.A., Hoekstra, J.B., et al. (2005) Value of Routine Funduscopy in Patients with Hypertension: Systematic Review. BMJ, 331, 73. https://doi.org/10.1136/bmj.331.7508.73

[28] Dimmitt, S.B., West, J.N., Eames, S.M., et al. (1989) Usefulness of Ophthalmoscopy in Mild to Moderate Hypertension. The Lancet, 1, 1103-1106. https://doi.org/10.1016/S0140-6736(89)92384-2

[29] Wong, T. and Mcintosh, R. (2005) Hypertensive Retinopathy Signs as Risk Indicators of Cardiovascular Morbidity and Mortality. British Medical Bulletin, 73-74, 57-70. https://doi.org/10.1093/bmb/ldh050 